\title{
Use of the sterile insect technique in New Zealand: Benefits and constraints
}

\author{
R.M. Horner ${ }^{1}$, J.T.S. Walker ${ }^{2}$, D.J. Rogers ${ }^{2}$, P.L. Lo² ${ }^{2}$ and D.M. Suckling ${ }^{1,3}$ \\ ${ }^{1}$ The New Zealand Institute for Plant \& Food Research Limited, Private Bag 4704, Christchurch \\ Mail Centre, Christchurch 8140, New Zealand \\ ${ }^{2}$ The New Zealand Institute for Plant \& Food Research Limited, Hawke’s Bay, Private Bag 1401, \\ Havelock North, New Zealand \\ ${ }^{3}$ School of Biological Sciences, University of Auckland
}

Corresponding author: rachael.horner@plantandfood.co.nz

\begin{abstract}
The sterile insect technique (SIT) is increasingly being evaluated as a potential complementary strategy for pest suppression or elimination. New Zealand's export fruit sector has an imperative to meet strict international phytosanitary requirements, together with increasing market demand for residue-free produce. SIT is a pest-specific method of insect control that can complement current Integrated Pest Management (IPM) strategies. Successful SIT presents significant challenges: the target pest must be a good candidate for suppression, and strong stakeholder and community commitment is required to achieve and maintain suppression until area-wide elimination is achieved. Emerging sterilisation technologies and refinement of existing methods are making this technology progressively more efficient and cost-effective. This study reviewed the advantages of including SIT in an IPM programme and described the first use of codling moth SIT in New Zealand. A pilot programme is currently underway to evaluate its potential to achieve local elimination of codling moth in Central Hawke's Bay apple orchards.
\end{abstract}

Keywords Sterile Insect Technique, integrated pest management, apples, codling moth, local elimination

\section{INTRODUCTION}

For several insect pests worldwide the sterile insect technique (SIT) is being increasingly used as an environmentally-friendly component of area-wide integrated pest management (AW-IPM) programmes (Klassen \& Curtis 2005). The sterile insect technique is a biological control method that involves the sterilisation of reared insects using either ionizing radiation, genetic modification or exposure to chemicals. Large numbers of sterile or partially sterile insects when released into the environment compete with the wild males to mate with wild females, reducing the number of successful matings and offspring (Lance \& McInnis 2005). Inducing inherited sterility is the preferred method, as it not only requires a lower dose of radiation than immediate sterility, but also released sterile insects have higher fitness and competitiveness. That way, the radiation-induced deleterious effects are inherited by the $\mathrm{F} 1$ generation and penetration into the wild population is far 
greater for every sterile male that mates with a wild female, with collapse at F2 (Carpenter et al. 2005).

SIT can help provide a market advantage by locally eradicating or suppressing an insect pest and thereby gaining area freedom. For example, in Thailand, two tephritid fruit fly species, the guava fruit fly Bactrocera correcta and the oriental fruit fly Bactrocera dorsalis, were considered the most significant horticultural insect pests, causing considerable loss of fruit quality and yield (Orankanok et al. 2007). The flies limited domestic commercialisation and prevented access to international markets. An ongoing AW-IPM programme since 1991 involves combining SIT with other IPM methods such as bait sprays and orchard sanitation. Damage was reduced from $80 \%$ before programme implementation to $3.6 \%$ over 5 years in Ratchaburi Province, and from 42.9 to $15.5 \%$ in Pichit Province over 2 years. This pre-harvest suppression combined with postharvest risk mitigation measures has allowed mangoes to be exported to high value markets that have strict quarantine requirements such as Japan (Orankanok et al. 2007). A benefit: cost ratio of 7.5:1 and a net benefit of US\$7.5 million was estimated for the mango growers in Ratchaburi Province since the beginning of the programme. This compares with a 2:1 benefit: cost ratio and a net benefit of US\$0.17 million using conventional methods (Enkerlin 2001). In Israel, a suppression programme targeting Mediterranean fruit fly (Medfly), Ceratitis capitata, resulted in increased fresh vegetable exports from the Avara region that are now valued at almost US\$30 million per year (Cayol et al. 2004).

The only example of the use of SIT in New Zealand was as part of the 1999-2006 area-wide programme to eradicate the Australian painted apple moth, Teia anartoides (Suckling et al. 2007). A combination of methods was used. SIT was tested in 2002 and releases started in 2003 when trap catches indicated a population at $\sim 1 \%$ of the population in previous years. An estimated overflooding ratio of 100:1 following an aerial Bacillus thuringiensis kurstaki (Btk) spray programme drove the wild population to extinction (Suckling et al. 2007). This programme was a small-scale one, where only a few thousand insects were released per week, targeting small delimited populations. The technology, however, even when used on a small scale has a number of advantages that when deployed can cost-effectively restore biosecurity (Suckling 2003).

This paper focuses on the potential for future use of SIT in pest management and suppression on a larger, area-wide scale in New Zealand. We will illustrate the concept using a pilot codling moth (Cydia pomonella) eradication, to be reported more fully elsewhere.

\section{ADVANTAGES OF INCLUDING SIT IN AN IPM PROGRAMME}

SIT provides economic benefits and environmental advantages when integrated with other conventional and biological methods. This integration enables the application of totally biological systems for managing insect pests. SIT also exhibits increased efficiency with decreasing pest population density. Therefore, it is the only environmentally-friendly technology that can eradicate insect pests if applied area-wide.

\section{Economic benefits}

The financial gain can far outweigh the cost of SIT used for suppression or eradication, which has been demonstrated in a number of cases. Mexico protects a horticultural export market of over US\$3 billion/year with an annual investment of only $\sim 25$ million (Hendrichs 2000). When implemented on an area-wide basis and when coupled with an insect rearing and sterilisation facility, SIT can be potentially cost-competitive with conventional pest control over time. Pest control can be optimised and there are significant market access benefits (Mumford 2005). The economic benefit of eradicating codling moth from Brazil was valued at US\$100 million (Kovaleski \& Mumford 2007). One of the challenges frequently faced by new SIT proposals is the capital cost of building an insect rearing facility. However, sterile 
insects can be imported, for example, South Africa imported sterile Canadian insects for local release (Blomefield et al. 2011), thereby overcoming the capital investment challenge.

\section{Legislative framework}

The legislative framework allowing SIT to be used for controlling species already present in New Zealand is relatively straightforward compared with that for some other types of pest management technologies. For example, there are no restrictions meeting the stringent requirements of the Hazardous Substances and New Organisms Act (1996), which often restricts the use of other pest management technologies such that they become impractical to consider e.g. those involving insect pathogens not currently in New Zealand, or some pesticides which are subject to reassessment. If the SIT programme is reliant on the importation of sterile insects from overseas, even for organisms not new to New Zealand (such as codling moth), an Import Health Standard and permit to import live animals is still necessary under the Biosecurity Act (1998). No registration is required under the Agricultural Compounds and Veterinary Medicines (ACVM) Act 1997.

\section{Reduced environmental impact}

There is a public preference for pest suppression tactics such as SIT that involve lower personal and environmental impact over other interventions, including aerial or ground spraying (Gamble et al. 2010). In British Columbia, a long-running programme was established to mass-rear and release sterile codling moths for suppression, partly because of pressure from peri-urban residential owners concerned with the application of organophosphate insecticides in nearby orchards. Similar concerns also exist in Hawke's Bay, where there is extensive crossover between apple production and residential borders. Under current Integrated Fruit Production (IFP) protocols, apple growers apply insecticides three to eight times a season for codling moth, depending on their use of mating disruption (Walker et al. 2013). Mating disruption with a multiple species product supports pest suppression and helps to provide market access without insecticide residues for a significant portion of growers (Walker et al. 2015). SIT in conjunction with other insect controls could further reduce the frequency of insecticide use and residential concern.

\section{Insecticide elimination and resistance management}

Sterile insect releases could help to manage insecticide resistance by significantly reducing the risk, or delaying its onset. Some insecticides are also being banned by regulatory bodies because they no longer meet environmental and/or human health and safety regulations. SIT could replace banned insecticides. Recent developments in Australia with the loss of organophosphates fenthion and dimethoate for field control of Queensland fruit fly (Qfly) have allowed that pest to expand its overwintering geographic distribution significantly to the south and east. One response has been for the South Australian authorities to build a new sterile insect factory at Port Augusta as part of a larger programme to control this expanding pest that threatens local and export production (SITplus 2016). Current suppression controls are seen as inadequate, so a diverse range of new and supplementary pest control methods are under investigation to support this SIT initiative.

\section{Efficiency at low population densities}

SIT is effective even when pest populations are at a very low density and released sterile insects actively seek and mate with rare insects. Other methods fail to achieve cost-effective pest control when the target population is very small. Over time the sterile male to fertile male ratio increases, sterile mating rates increase, and the target population continually diminishes (Knipling 1955). 


\section{Reduced surveillance and intervention costs}

Successful local eradication of codling moth across production areas has the potential to reduce surveillance and intervention costs for growers. It could also enhance access to high value markets where there is a nil tolerance for codling moth, although area freedom is likely to require regulatory approval and implementation of appropriate monitoring and reporting measures.

\section{A PILOT ERADICATION OF CODLING MOTH IN CENTRAL HAWKE'S BAY}

The goal of our evaluation of SIT for codling moth control in New Zealand is to determine if local eradication, or at least a significant reduction in population, can be achieved. Our major fruit importers demand pest-free, low residue or residue-free fruit. Codling moth is a pest of quarantine concern in many of New Zealand's export programmes, as there is a zero codling moth tolerance policy in many of the high value Asian markets. SIT coupled with reduced pesticide use would also be compatible with European demand for low-residue or residue-free fruit.
SIT is being implemented alongside other IPM methods including mating disruption, phenology and threshold-based pheromone trap sprays, and on-orchard alternate host removal. Expansion of the pilot programme to the wider Hawke's Bay area and Nelson will be considered if eradication can be achieved, and the logistics, economics and likelihood of success of a wider SIT programme are considered.

Three large orchards (approximately 200 ha in total) have been included in the SIT pilot programme that began in October 2014. They are located on the Ruataniwha Plains in Central Hawke's Bay (CHB), which has about 450 ha of apple orchards and is geographically isolated by $80 \mathrm{~km}$ from the main growing area in Hawke's Bay, the Heretaunga Plains (Figure 1). There are seven orchards in CHB surrounded by pastoral farms. These orchards are therefore relatively isolated, with relatively few sources of codling moth within $5-10 \mathrm{~km}$. They have a history of very low codling moth activity after $>15$ years of adhering to Pipfruit New Zealand's IFP programme.

Mass-reared codling moth irradiated at $200 \mathrm{~Gy} 150 \mathrm{~Gy}^{*}$ have been imported from the Okanagan-Kootenay *Correction Sterile Insect Release (OKSIR) facility in Osoyoos, made by aut

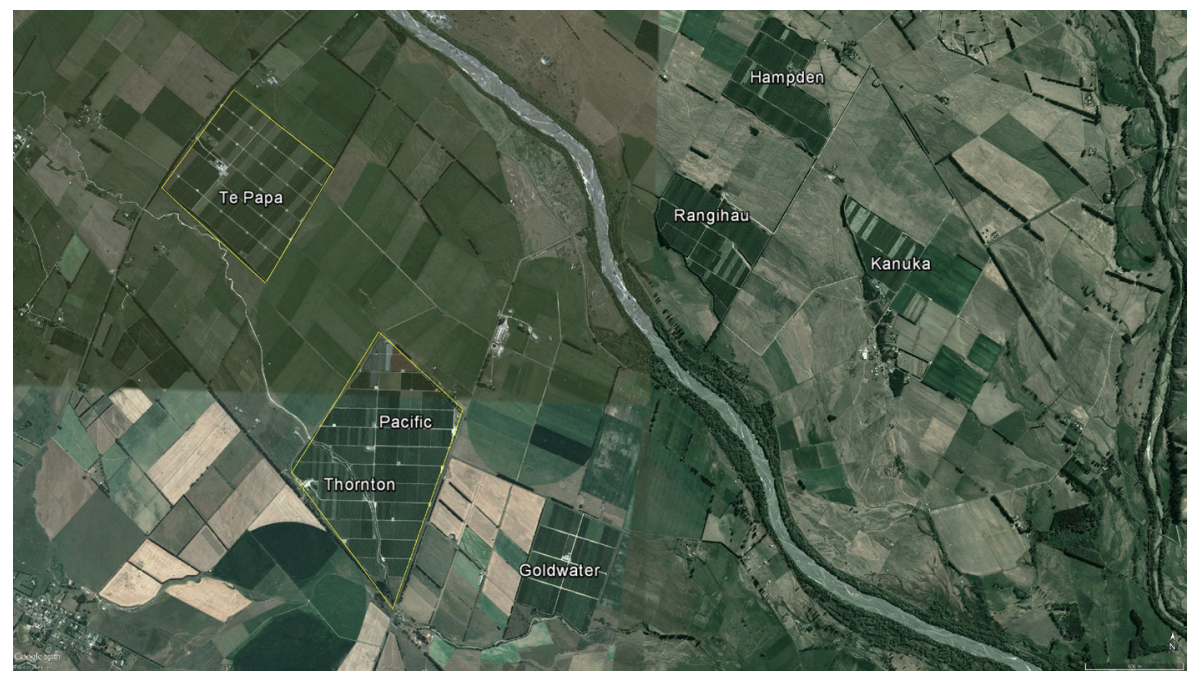

Figure 1 The location of Te Papa, Thornton and Pacific apple orchards on the Ruataniwha Plains, Central Hawke's Bay, New Zealand. The borders of these orchards receiving releases of sterile codling moths release are highlighted in yellow. These apple orchards are isolated from the main orchard district (80 $\mathrm{km}$ to the south west). 


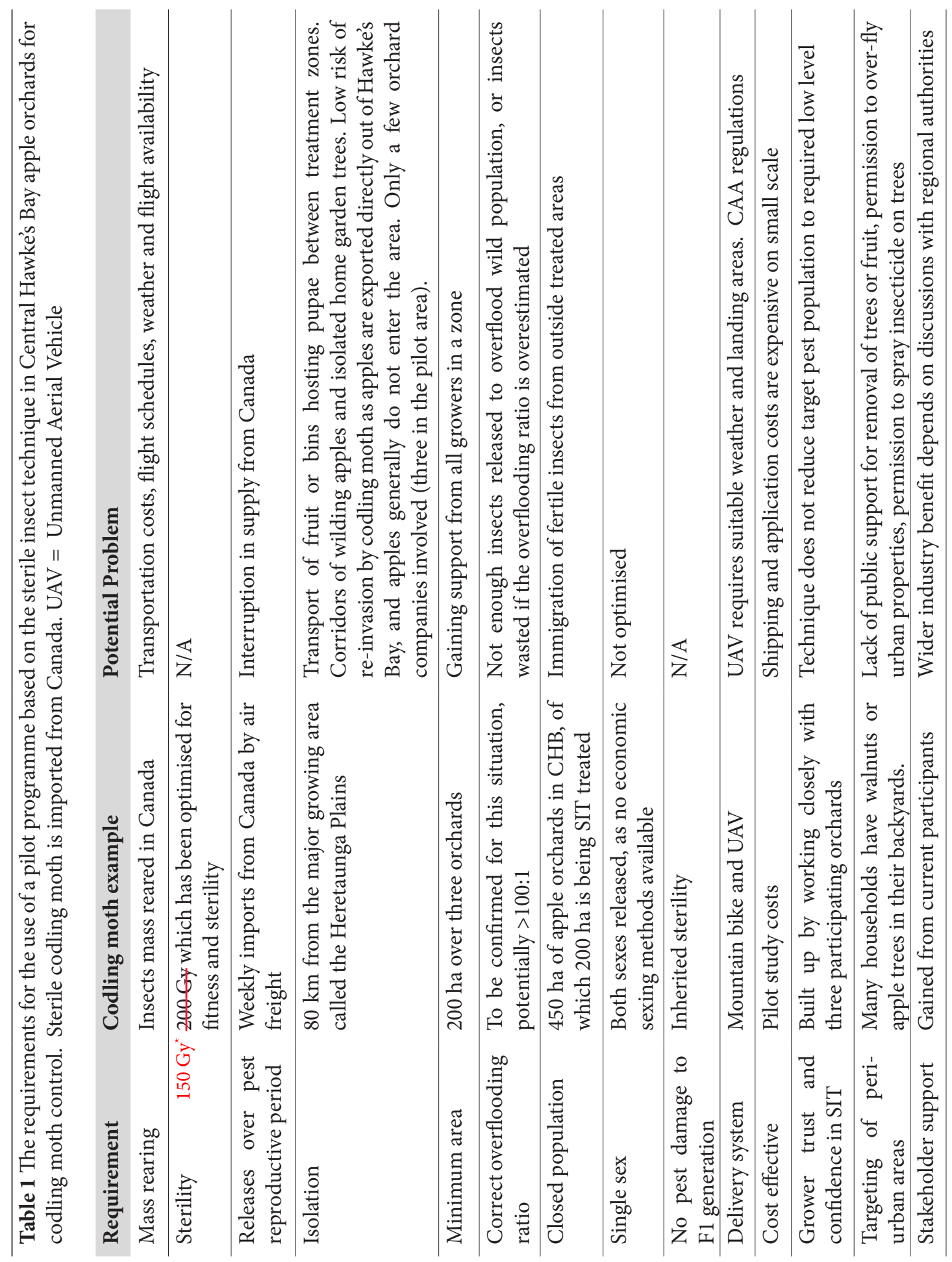


British Columbia, Canada. Some 400,000 sterilised adult moths were imported from November 2014 to March 2015 and about 480,000 more in 2015 and 2016. An import health standard was issued for the import of commercially-packaged insects. The consignments were accompanied by certificates of sterilisation and they were certified as free of from associated organisms or diseases.

The fitness of mass-reared, sterilised insects before and after chilling and airline freight has been extensively tested. No significant reduction in fitness (at 200 Gy) has been found in flight ability (Carpenter et al. 2013), mating ability, fecundity and fertility (Bloem et al. 1999) or longevity (Blomefield et al. 2011) after up to $72 \mathrm{~h}$ in transit. Similar fitness performance tests were undertaken on insects imported into New Zealand after 35 hours in transit (unpublished data).

Previous research showed mating compatibility among populations of codling moth from different geographic origins, including mating between populations from Canada and New Zealand (Taret et al. 2010).

Extensive codling moth SIT release programmes in Canada (Bloem et al. 2007) and pilot programmes in South Africa and Washington have greatly improved quality management of the insects, which over time has enhanced the efficacy of SIT for codling moth control.

The insects were initially released in Hawke's Bay from containers transported on mountain bikes at weekly or two-weekly intervals. In the near future, the mountain bike method will be replaced by a remotely-controlled Unmanned Aerial Vehicle (UAV) equipped with a precision guidance system and controlled moth-release mechanism. The UAV was developed in New Zealand in conjunction with M3 Consulting Group (Phoenix, Arizona, USA). The UAV will significantly improve the frequency and accuracy of SIT, compared with ground-based releases of sterile insects.

\section{REQUIREMENTS FOR THE SUCCESSFUL INTEGRATION OF SIT INTO AN IPM PROGRAMME}

Suppressing highly mobile pests on an area-wide basis is more effective, profitable and environmentally-friendly than on an individual orchard basis because of economies of scale. In particular, coordinated pest suppression offers theoretical advantages from farmers in a region facing pest movement (Byers \& Castle 2005). However, the practical success of an area-wide IPM programme including SIT relies upon an holistic and multidisciplinary approach and effective management. It also requires significant funding from a diverse range of financial supporters (Klassen 2005). The requirements of successful integration of codling moth SIT into the existing pipfruit IPM programme are discussed in Table 1.

Area freedom from codling moth that will enhance market access will require widespread uptake of the SIT. This may not always be possible. Since 1981 a private firm has applied SIT for onion fly Delia obliqua in The Netherlands. Individual farmers contract for SIT independently of their neighbours, many of whom rely on insecticidal control. Because an area-wide approach has not been established, and sterile flies are not released in a contiguous block, the programme has not expanded beyond $16 \%$ of the onion production area. It is therefore not as effective as it could be if the SIT was more widespread (Loosjes \& Tan 2000). This example illustrates the difficulty of maintaining area freedom, which results in SIT being used mainly for pest suppression rather than eradication. In order for an area-wide codling moth SIT programme to be successful, consultation and collaboration between growers, regional councils and the wider public will be essential.

\section{THE FUTURE OF SIT IN NEW ZEALAND}

The current pilot programme involving weekly importation and release of sterile moths from Canada is being undertaken to determine the feasibility of eradication in a relatively small area in Hawke's Bay, with potential to expand to wider pipfruit-growing areas. The pilot programme is important for developing and testing the logistics of transport and release, the costs and feasibility 
of success, as well as identifying key components of future success. The data will be used as part of a cost: benefit analysis of any programme expansion.

While there are no other sterile insect programmes as advanced as the codling moth example in New Zealand at the present time, the increasing cost of incursions of exotic insects into New Zealand warrants investigation and development of all potential methods of control and eventually eradication. Emerging sterilisation technologies are making SIT progressively more efficient and cost-effective. The Trojan female technique is a new approach on the traditional SIT model, using naturally occurring maternally inherited mitochondrial (mtDNA) mutations that affect male, but not female, reproductive fitness. Adult "Trojan females" carrying mutant mtDNA would be introduced into the wild population as either single large releases or relatively few small repeat releases. 'Trojan females' and their female descendants carrying these mutations would produce sterile male equivalents over multiple generations. This means fewer, larger releases will provide effective and persistent control, more quickly. mtDNA is greatly conserved among eukaryotes, suggesting this approach would have broad application in pest control (Gemmell et al. 2013). Sex-specific sterility may be achieved by developing transgene-based sterile insect technology. Current somatic TALEN and CRISPR technologies provide a future in the area of insect functional genetics (Xu et al. 2014). There is also potential for lure and sterilise technologies (El-Sayed et al. 2009).

There are several other insect orders besides Lepidoptera and Diptera that can be targeted with SIT for potential suppression or eradication. SIT programmes involving eradication of the boll weevil in the United States, Anthonomus grandis grandis (Klassen \& Earle 1970), and an eradication of sweet potato weevil, Cylas formicarius, in Japan, provide examples of SIT within Coleoptera (Kohama et al. 2003). The mass rearing and sterilisation of Qfly in Australia provides the option of eradication by SIT in the case of an incursion into New Zealand. In such a case, SIT is a suitable technology for small-scale eradications. In a number of countries the surveillance for an incursion of Medfly is coupled with a capacity for sterile insect releases on this scale, but in those cases the technology is already developed.

Early experiments into SIT for the eradication of brown marmorated stink bug are also being carried out by our laboratory using model species e.g. green vegetable bug Nezara viridula and USDA ARS co-operators (Carpenter et al. unpublished data). It is likely that the scope of orders, and the number of species targeted with SIT will increase as countries realise the potential of SIT for eradication, and pest management, where eradication is not possible.

\section{ACKNOWLEDGEMENTS}

This work was funded by the Joint FAO/IAEA Programme of Nuclear Techniques in Food and Agriculture, Pipfruit New Zealand Inc., and the Better Border Biosecurity (B3) programme (www.b3nz.org). Thanks to the OkanaganKootenay Sterile Insect Release Programme in British Columbia, Canada for providing the sterile codling moths for the pilot study.

\section{REFERENCES}

Bloem S, Bloem KA, Carpenter JE, Calkins CO 1999. Inherited sterility in codling moth (Lepidoptera: Tortricidae): Effect of substerilizing doses of radiation on insect fecundity, fertility and control. Annals of the Entomological Society of America 92: 222229.

Bloem S, Carpenter J, McCluskey A, Fugger R, Arthur S, Wood S 2007. Suppression of the codling moth Cydia pomonella in British Columbia, Canada using an area-wide integrated approach with an SIT component. In: Vreysen MJB, Robinson AS, Hendrichs J eds. Area-Wide Control of Insect Pests. Springer Netherlands. Pp. 591-601.

Blomefield T, Carpenter JE, Vreysen MJB 2011. Quality of mass-reared codling moth (Lepidoptera: Tortricidae) after longdistance transportation: 1. Logistics of shipping procedures and quality parameters 
as measured in the laboratory. Journal of Economic Entomology 104: 814-822.

Byers JA, Castle SJ 2005. Areawide models comparing synchronous versus asynchronous treatments for control of dispersing insect pests. Journal of Economic Entomology 98: 1763-1773.

Carpenter J, Bloem S, Marec F 2005. Inherited sterility in insects. In: Sterile Insect Technique. Springer. Pp. 115-146.

Carpenter JE, Blomefield T, Hight SD 2013. Comparison of laboratory and field bioassays of laboratory-reared Cydia pomonella (Lepidoptera: Tortricidae) quality and field performance. Journal of Applied Entomology 137: 631-640.

Cayol J, Rössler Y, Weiss M, Bahdousheh M, Omari M, Hamalawi M, Almughayyar A, Barnes B 2004. Fruit fly control and monitoring in the Near East: shared concern in a regional transboundary problem. Proceedings of the 6th International Symposium on fruit flies of economic importance, Stellenbosch, South Africa, 6-10 May 2002.: 155-171.

El-Sayed AM, Suckling DM, Byers JA, Jang EB, Wearing $\mathrm{CH}$ 2009. Potential of "lure and kill" in long-term pest management and eradication of invasive species. Journal of Economic Entomology 102: 815-835.

Enkerlin WR 2001. An economic assessment for oriental fruit fly control using the sterile insect technique (SIT) in Thailand: a case study for the mango production areas of Paktor District. In Report to the IAEA. IAEA, Vienna, Austria. Pp. 11.

Gamble JC, Payne T, Small B 2010. Interviews with New Zealand community stakeholders regarding acceptability of current or potential pest eradication technologies. New Zealand Journal of Crop and Horticultural Science 38: 57-68.

Gemmell NJ, Jalilzadeh A, Didham RK, Soboleva T, Tompkins DM 2013. The Trojan female technique: a novel, effective and humane approach for pest population control. Proceedings of the Royal Society of London B: Biological Sciences 280.
Hendrichs J 2000. Use of the sterile insect technique against key insect pests. Sustainable Development International 2: 75-79.

Klassen W 2005. Area-Wide integrated pest management and the sterile insect technique. In: Dyck VA, Hendrichs J, Robinson AS eds. Sterile Insect Technique. Springer Netherlands. Pp. 39-68.

Klassen W, Earle N 1970. Permanent sterility induced in boll weevils with busulfan without reducing production of pheromone. Journal of Economic Entomology 63: 1195-1198.

Klassen W, Curtis CF 2005. History of the Sterile Insect Technique. In: Dyck VA, Hendrichs J, Robinson AS eds. Sterile Insect Technique. Springer Netherlands. Pp. 3-36.

Knipling E 1955. Possibilities of insect control or eradication through the use of sexually sterile males. Journal of Economic Entomology 48: 459-462.

Kohama T, Yamagishi M, Kuba H, Kinjo K 2003. A progress report on the eradication program of the sweet potato weevil, Cylas formicarius (Fabricius)(Coleoptera: Brentidae), with both male annihilation using sex pheromone and sterile insect releases in Kume Island, Okinawa, Japan.

Kovaleski A, Mumford J 2007. Pulling out the evil by the root: The codling moth Cydia pomonella eradication programme in Brazil. In: Vreysen MJB, Robinson AS, Hendrichs J eds. Area-Wide Control of Insect Pests: From Research to Field Implementation. Springer Netherlands, Dordrecht. Pp. 581-590.

Lance D, McInnis D 2005. Biological basis of the sterile insect technique. In: Sterile Insect Technique. Springer. Pp. 69-94.

Loosjes M, Tan K-H 2000. The sterile insect technique for commercial control of the onion fly. Area-wide control of fruit flies and other insect pests. Joint proceedings of the international conference on area-wide control of insect pests, 28 May-2 June, 1998 and the Fifth International Symposium on Fruit Flies of Economic Importance, Penang, Malaysia, 1-5 June, 1998.: 181-184.

Mumford J 2005. Application of benefit/cost 
analysis to insect pest control using the sterile insect technique. In: Sterile Insect Technique. Springer. Pp. 481-498.

Orankanok W, Chinvinijkul S, Thanaphum S, Sitilob P, Enkerlin W 2007. Area-wide integrated control of oriental fruit fly Bactrocera dorsalis and guava fruit fly Bactrocera correcta in Thailand. In: AreaWide Control of Insect Pests. Springer. Pp. 517-526.

SITplus 2016. Delivering a solution for Queensland fruit fly. In. http://pir.sa.gov. au/data/assets/pdf file/0005/242744/ SITplusPartnershipBrochure.pdf.

Suckling D, Barrington A, Chhagan A, Stephens A, Burnip G, Charles J, Wee S 2007. Eradication of the Australian painted apple moth Teia anartoides in New Zealand: trapping, inherited sterility, and male competitiveness. In: Area-wide Control of Insect Pests. Springer. Pp. 603-615.

Suckling DM 2003. Applying the sterile insect technique for biosecurity: Benefits and constraints. New Zealand Plant Protection 56: 21-26.
Taret G, Sevilla M, Wornoayporn V, Islam A, Ahmad S, Caceres C, Robinson AS, Vreysen MJB 2010. Mating compatibility among populations of codling moth Cydia pomonella Linnaeus (Lepidoptera: Tortricidae) from different geographic origins. Journal of Applied Entomology 134: 207-215.

Walker J, Park N, Butcher M, Zydenbos S 2015. Apple Futures: New Zealand's low pesticide residue apple production programme. New Zealand Plant Protection 68: 282-290.

Walker J, Lo P, Horner R, Park N, Hughes J, Fraser $\mathrm{T}$ 2013. Codling moth (Cydia pomonella) mating disruption outcomes in apple orchards. New Zealand Plant Protection 66: 259-263.

Xu J, Wang Y, Li Z, Ling L, Zeng B, James AA, Tan A, Huang Y 2014. Transcription activator-like effector nuclease (TALEN)-mediated femalespecific sterility in the silkworm, Bombyx mori. Insect molecular biology 23: 800-807. 